\title{
Gênero e o Declínio das Políticas Públicas.
}

\section{Gender and the Decline of Public Policies.}

\author{
Margarete Panerai Araujo* \\ Kellen Cristina Varisco Lazzari**
}

Resumo: Neste artigo procura-se fazer uma discussão sobre as políticas públicas para as mulheres, sob a perspectiva de gênero, em especial em duas gestões do estado do Rio Grande do Sul, aquelas entre os anos de 2011 e 2018. A partir da pesquisa bibliográfica e documental acerca do tema, este trabalho tem o objetivo de mostrar como a construção social de gênero influencia não apenas as relações entre homens e mulheres, marcadas na sociedade brasileira por uma grande desigualdade, mas também como ela intervém na construção, ou melhor, na falta de políticas públicas direcionadas para as mulheres. Para examinar essas questões o presente artigo discorrerá a respeito de gênero, violência de gênero e políticas públicas e sociais.

Palavras-chave: Gênero. Violência de gênero. Políticas públicas.

Abstract: This article seeks to make a discussion about public policies for women, from the perspective of gender, especially in two managements of the state of Rio Grande do Sul, those between the years 2011 and 2018. Based on the bibliographic and documentary research on the theme, this paper aims to show how the social construction of gender influences not only the relations between men and women, marked in Brazilian society by a great inequality, but also how it intervenes in the construction, Or rather, in the absence of public policies directed towards women. To examine these issues this article will discuss genderrelated, gender violence and public and social policies.

\footnotetext{
* É pós-doutora em Administração Pública e de Empresas em Políticas e Estratégias pela FGV EBAPE/RJ (2013); e pós-doutora em Comunicação Social, Cidadania e Região na UMESP nas Cátedras UNESCO e Gestão de Cidades (2010). Professora-pesquisadora da Universidade La Salle, vinculada ao Programa de Pós-graduação em Memória Social e Bens Culturais na linha de pesquisa de Memória e Gestão Cultural e do Observatório Unilasalle: Trabalho, Gestão e Políticas Públicas.

** Advogada, graduada em Ciências Jurídicas e Sociais pela Pontifícia Universidade Católica do Rio Grande do Sul (1993); Especialização em Direito do Consumidor e Direitos Fundamentais pela Universidade Federal do Rio Grande do Sul (2008); Mestre em Memória Social e Bens Culturais pela Universidade La Salle (2014); Doutoranda em Memória Social e Bens Culturais pela Universidade La Salle, 2019. Participa do Grupo de Pesquisa: Memória e Políticas Públicas suas implicações.
} 
Revista Brasileira de História \& Ciências Sociais - RBHCS

Vol. $12 \mathrm{~N}^{\circ} 23$, Janeiro - Junho de 2020

Key words: Gender. Gender violence. Public policies.

\section{Introdução}

No Brasil, como em quase todos os países, as mulheres eram tidas como seres inferiores e excluídas das decisões políticas e sociais, visto que só em 1932, com o Decreto $\mathrm{n}^{\mathrm{O}}$ 21.076, conquistaram o direito de votar (ARAÚJO, 2003). Excluir é sinônimo de separar, excetuar; expulsar, rejeitar, colocar à margem da cidadania. Assim, ocorreu nos mais remotos tempos e ocorre ainda hoje com várias pessoas, sejam elas jovens, velhos, homens, mulheres, brancos, negros, índios, operários, presidiários, prostitutas, homossexuais, pobres e nos mais diversos lugares, cidades, países.

A exclusão é o contrário da cidadania e é na diferença entre esses dois conceitos que se pode definir exclusão (PESAVENTO, 2001). Cidadania e exclusão são resultados de uma construção social, modelos de representações sociais. São as representações sociais que permitem construir a identidade social de um grupo, numa mesma sociedade, que produzem uma "cadeia simbólica de sentidos”. E essas mesmas representações sobre o outro produzem a exclusão social. Todas as formas de exclusão levam à vulnerabilidade do excluído de alguma forma ou momento, uma vez que o coloca à margem da cidadania.

Pesavento (2001, p. 19) alerta que “[...] a noção de exclusão se introjeta e se reflete na autoestima”, ou seja, o sentir-se excluído, rejeitado “[...] percorre o domínio das sensibilidades e penetra fundo nas experiências de vida e na cotidianidade", que, para a autora, “[...] revela a presença do eu como agente e matriz das sensações e sentimentos. Ela começa no indivíduo que, pela reação do sentir, expõe o seu íntimo" (PESAVENTO, 2007, p. 13). É assim que muitas mulheres ainda se sentem como se fossem menos qualificadas para a vida em sociedade, como se fossem seres inferiores, não merecedoras de todos os direitos individuais e sociais.

Em grande parte das sociedades e a brasileira não é exceção, os “códigos”, as representações sociais que giram em torno da mulher, fazem com que se estabeleçam inúmeras diferenças, desigualdades que passam a ser justificativas usadas para as diferentes formas de excluir, dominar, oprimir, impedir as mesmas oportunidades e direitos às mulheres. Enfim, chega-se ao contraponto já 
abordado: a ausência da cidadania. E a desigualdade é um dos fatores que geram a violência contra elas.

Destarte, fruto de uma ideologia sexista, de uma cultura patriarcal, onde predomina o machismo e a misoginia e pela falta de ações mais efetivas por parte do Estado, as mulheres ainda hoje são alvos de violência de todos os tipos apenas pelo fato de serem mulheres. Os comportamentos violentos são naturalizados, uma vez que fazem parte da construção social proveniente do patriarcalismo e, diante dessa realidade, tem-se dificuldade em punir os agressores devido a essa cultura de superioridade do gênero masculino em relação ao feminino, ocasionando, dessa forma, a violência de gênero.

De tal modo que, diante dessa realidade de violência, as mulheres há décadas lutam, pressionam o Estado por políticas públicas que visem à igualdade de direitos e, por conseguinte, pelo fim dessa violência contra elas. Assim, este trabalho tem o objetivo de mostrar como a construção social de gênero influencia não apenas as relações entre homens e mulheres, marcadas na sociedade brasileira por uma grande desigualdade, mas também como ela intervém na construção, ou melhor, na falta de políticas públicas direcionadas para as mulheres. Considerando, portanto, que a violência de gênero aparece em índices elevados no Brasil, este estudo faz um recorte e foca na análise de duas gestões do Estado do Rio Grande do Sul (RS), no período entre os anos de 2011 e 2018. Tendo em vista que, segundo dados do Observatório Estadual da Secretaria de Segurança Pública do Rio Grande do Sul (SSP/RS) houve um aumento de 56\% nos casos de feminicídios entre o final das duas últimas gestões do governo estadual do RS. A SSP/RS (2019) mostra, ainda, que os números de feminicídios continuam aumentando no Estado, cresceram de oito vítimas em novembro de 2018 para 11 vítimas em novembro de 2019, correspondendo a um aumento de 37\%. Para examinar essas questões o presente artigo discorrerá a respeito de gênero, violência de gênero e políticas públicas e sociais.

\section{Desenrolar do gênero}

Esta parte do trabalho procura apresentar como a cultura machista e patriarcal influencia e contribui para ditar modos de ser, de padronizar comportamentos, acentuar percepções consideradas como "naturais" e, inclusive, 
podem reiterar relações de gênero e de poder. O conceito de gênero tem inúmeras interpretações e foi absorvido pelo feminismo e pela produção acadêmica sobre mulheres nos anos 1970. Neste trabalho, entende-se que gênero é uma construção social, ou seja, são os significados construídos culturalmente do que é masculino e feminino, bem como de suas diferenças. Sendo assim, trata-se de um conceito aberto, variável conforme a sociedade em que se vive (LAZZARI, 2014).

Ao considerar gênero como construção cultural significa que uma parte dessa construção ocorre em processos de ensino-aprendizagem, nos quais se está inserido ao longo da vida. Em virtude de ser construído, implica dar-se conta de que gênero é relacional, não se produz no vazio, e sim que se vivencia cotidianamente e se posiciona conforme a raça, a etnia, a sexualidade, a religião e a nacionalidade. Significa considerá-lo como um organizador cultural, onde todas as instituições e práticas culturais são marcadas por ele (MEYER, 2003).

Para Stolcke (2004), o termo "gênero" aparece, pela primeira vez, na escrita de Margaret Mead, em 1949, ainda que de modo menos claro. Afirma ainda que gênero foi usado, na década de 1970, para se referir à construção social e não em bases biológicas, à desigualdade entre homens e mulheres, e à dominação delas pelos homens.

O vocábulo "gênero", segundo Giordani, pode ser compreendido como um instrumento que "[...] facilita a percepção das desigualdades sociais e econômicas entre mulheres e homens, que se devem à discriminação histórica contra as mulheres” (GIORDANI, 2006, p. 99). Para Scott é:

Uma maneira de indicar as "construções sociais" - a criação inteiramente social das ideias sobre os papéis próprios aos homens e às mulheres (SCOTT, 1990, p. 7); é um elemento constitutivo de relações sociais baseado nas diferenças percebidas entre os sexos, e o gênero é uma forma primeira de significar as relações de poder (SCOTT, 1990, p. 21).

Pode-se sintetizar que "gênero" é um conceito "[...] mais amplo que a noção de patriarcado, que é o regime da dominação-exploração das mulheres pelos homens" (SAFFIOTI, 2004, p. 44). O patriarcado é uma forma de organização social na qual as relações são regidas por dois princípios básicos: 1) as mulheres estão hierarquicamente subordinadas aos homens; e 2) os jovens estão hierarquicamente subordinados aos homens mais velhos. A supremacia masculina, ditada pelos valores do patriarcado, atribuiu maior valor às atividades 
masculinas, em detrimento das atividades femininas; legitimou o controle da sexualidade, dos corpos e da autonomia femininas, e estabeleceu papéis sexuais e sociais, nos quais o masculino tem vantagens e prerrogativas (MILLET, 1970; SCOTT, 1995).

Para Teles e Melo (2002), não são as diferenças biológicas entre os sexos que determinam a violência de gênero ou a violência contra a mulher, mas os papéis sociais impostos às mulheres e aos homens, que são reforçados pelas culturas patriarcais que estabelecem relações de dominação e violência entre os sexos. Considera-se que apenas o sexo não define o conceito de "gênero", mas não se pode deixá-lo de lado, como talvez quiseram afirmar Teles e Melo (LAZZARI, 2014).

Enfim, para Stolcke (2004), independentemente das teorias sobre a construção sociocultural do sexo, corpos sexuados e sexualidade, para quem estuda a dinâmica de uma sociedade o que importa é ver como é percebida a relação da natureza com a cultura na experiência humana, a fim de que se possa criar um mundo mais "justo e livre". Apesar de todas as transformações e conquistas das mulheres, essas continuam sendo estigmatizadas pela sociedade, em relação à questão de gênero, em face de serem retratadas como historicamente sempre foram: sensíveis, dependentes, emotivas, reprodutoras, mães, e outras características declaradas femininas pela sociedade, características essas que ainda são reproduzidas na construção de identidades. Isso fica demonstrado no fato de que se alguma mulher for o oposto dessas características, ela passará por uma “censura cultural”, por não corresponder ao que se espera de um comportamento de mulher, ou seja, o sexo e o gênero não se correspondem, atestando, dessa forma, que essas características são normativas culturais, que irão variar de sociedade para sociedade e conforme a época (STREY, 2002).

Vários padrões culturais continuam a reforçar a submissão da mulher e são responsáveis pela dificuldade que elas sentem em incriminar membros da família. Dentre eles podemos citar a ideia de que é dever da esposa obedecer e satisfazer às necessidades sexuais do marido. É comum também a visão da mulher como responsável por precipitar, facilitar e manter as situações de violência (DINIZ; PONDAAG, 2006, p. 247).

A forma pela qual essas diferenças entre os sexos é percebida é que origina as desigualdades entre homens e mulheres. A relação de poder e gênero é uma 
questão principal para Scott (1990) e a autora vai buscar a definição de poder em Foucault, que propõe o "poder sem rei”, o poder como uma relação assimétrica, desproporcional entre pessoas, entre grupos. "[...] há uma circulação de poder no interior do casamento e não uma divisão estanque do mesmo" (GROSSI, 1998, p. 305).

A existência do poder feminino é citada também por Michelle Perrot (2001). Ao contrário de Bourdieu (2003), que considera que as mulheres são dominadas pelo poder masculino, Perrot (2001) vê nessa relação a possibilidade de as mulheres exercerem "poderes", relativizando, dessa forma, o poder do homem, enquanto que, para o sociólogo, a dominação seria universalizante.

Seria com base nessa assimetria entre os poderes da mulher e do homem, da preponderância do poder do homem, que adviria o "direito" de agredi-la. Também o fato de a mulher "aceitar" a agressão como sendo normal, numa visão essencialista, proveniente de construções históricas, sociais - a mulher, como submissa ao homem (o homem dando ordens), essa constituição do sujeito (mulher), sua identidade de gênero, ou seja, a identidade que as mulheres e os homens assumem é constituída socialmente (LAZZARI, 2014).

Nesse caso, refere-se à força do discurso, o discurso que defende as ideias de um grupo. Os homens criam construções sociais para se beneficiarem e, de certa forma, satisfazerem aqueles que o aceitam (as mulheres), justificando, assim, o exercício do poder sobre esse grupo. “[...] Na realidade, o que faz que um corpo, gestos, discursos, desejos sejam identificados e constituídos como indivíduos, é precisamente isso um dos primeiros efeitos do poder" (FOUCAULT, 1999, p. 35). Portanto, a incidência do poder vai atuar sobre as mulheres de forma a produzir sua sujeição, dos seus comportamentos; como a naturalizar desigualdades, diferenças de gênero.

Desse modo, as mulheres internalizam essas desigualdades, assumindo os papéis de gênero que lhe são impostos. Grossi (2012) esclarece as diferenças entre papéis de gênero, identidade de gênero e sexualidade. A autora diz que "identidade de gênero" remete ao sentimento individual de identidade, e "papel de gênero" seria tudo o que é associado ao sexo biológico (macho ou fêmea), em determinada cultura.

Então, a construção de identidade de gênero, de forma simplificada, para Grossi (2010, p. 12), seria “[...] uma categoria pertinente para pensar o lugar do 
indivíduo no interior de uma cultura determinada”. Há a obrigatoriedade de alguém agir de determinada forma e não de outra. Assim, muitas vezes, são construídas relações entre mulheres agredidas e seus companheiros e, dessa maneira, dificilmente elas questionam o porquê dessa situação ou se poderia vir a ser diferente, pois é desse jeito que se identificam na sociedade. Para Grossi (1996), as diferenças, desigualdade social, econômica e política, que são perpetuadas pelas instituições sociais que recebem apoio das ideologias sexistas, classistas e racistas irão ocasionar a violência de gênero.

Violência pode ser conceituada como o não reconhecimento do outro, por meio de um excesso de poder, quando, através da força, da coerção, produzir-seá algum tipo de dano, violência (SANTOS, 2001). Cavalcanti (2007) a define como ato de brutalidade, abuso, constrangimento, discriminação, desrespeito, ofensa, agressão física, psíquica, moral, ou patrimonial contra alguém.

Arendt (1994) faz relação entre violência e poder. Considera que há um consenso entre os teóricos da política, tanto da esquerda como da direita, no sentido de que a violência é tão somente a mais flagrante manifestação de poder. Já na concepção de Heise, violência é

Um fenômeno extremamente complexo, com raízes profundas nas relações de poder baseadas no gênero, na sexualidade, na autoidentidade e nas instituições sociais e que em muitas sociedades, o direito (masculino) a dominar a mulher é considerado a essência da masculinidade (HEISE, 1994, p. $47 \mathrm{e}$ 48).

Quando se pensa em violência de gênero, Strey (2012) define como o ato violento em função do gênero ao qual a pessoa pertence, ou seja, a violência ocorre porque a vítima é homem ou mulher. Afirma, contudo, que é praticamente sinônimo de violência contra a mulher, pois elas são o maior número de vítimas.

Portanto, a violência contra a mulher não pode ser separada da categoria de gênero, pois deve ser entendida como reflexo de desigualdade social, econômica e política, reforçada por uma cultura e ideologia sexistas, racistas, classistas, de dominação e de exclusão. Tais relações estão mediadas por uma ordem patriarcal na sociedade brasileira, a qual atribui, aos homens, o direito a dominar e controlar suas mulheres, podendo, em alguns casos, chegar à violência física (LAZZARI, 2014).

Essa dominação masculina obtém na sociedade as condições para que haja 
sua disseminação, visto que muitas mulheres ainda se encontram como dependentes e submissas aos homens, tanto no que se refere a diversos planos, como econômico, social e cultural. Para Bourdieu (2003), a dominação masculina não se encerra na dependência e submissão das mulheres. Ela vai mais fundo: são concepções, significações criadas pela sociedade, que estão incutidas em homens e mulheres de maneira invisível, mascarando o poder do homem, que existe nas relações e tornando essas concepções, do que é ser homem e mulher, como naturais.

Os primeiros especialistas a estudarem a violência conjugal, conforme ressalta Hirigoyen (2006), assinalaram que ela se manifesta sob a forma de ciclos. Não é a única forma, mas a mais frequente. A violência que Hirigoyen (2006) descreve é composta por quatro fases que se retroalimentam: fase da tensão, na qual a violência acontece devido às tensões e preocupações que o agressor vive no seu dia a dia; fase da agressão, em que o agressor utiliza a violência física e, claro, a psicológica, que já ocorre desde a primeira etapa; fase do pedido desculpas ou do apaziguamento, nessa fase o agressor após extravasar suas tensões sobre sua mulher, por meio de violência física e psicológica, tende a minimizar seu comportamento agressivo, ou mesmo a anulá-lo; e, por fim, a fase da reconciliação ou lua de mel, o agressor se demonstra apaixonado, carinhoso, seduz a parceira, que passa a crer que ele realmente mudou; retorna à esperança de um casamento sem violência. Cunha (2007), por sua vez, inclui a fase da "lua de mel”, quarta fase, dentro da terceira, a do apaziguamento.

A violência contra a mulher é uma questão pública, que teve sua inclusão nas políticas públicas com o Movimento Feminista desde a Conferência das Nações Unidas sobre Direitos Humanos, em 1993, que reconheceu a violência contra as mulheres como violação aos direitos humanos. Os governos dos paísesmembros da ONU e as organizações da sociedade civil têm trabalhado para a eliminação dessa violência, também considerada como um problema de saúde pública. As primeiras políticas públicas com recorte de gênero, sob o impacto desses movimentos, foram implantadas na década de 1980, no Brasil (LAZZARI, 2014):

As mulheres, de alguma forma, sempre se fizeram presentes nas lutas por melhores condições de vida, nos movimentos sociais lutando pela democratização do regime e de reivindicações ligadas ao acesso a serviços 
públicos. Souza-Lobo salienta “[...] frequentemente as análises ignoraram que os principais atores nos movimentos populares eram, de fato, atrizes" (SOUZALOBO, 1991, p. 247).

\section{Metodologia}

O presente trabalho trata-se de uma pesquisa qualitativa, uma vez que tenciona os aspectos da realidade e centra-se na compreensão e explicação das dinâmicas das relações sociais, trabalhando com o universo de significados, motivos, aspirações, crenças, valores e atitudes (MINAYO, 2001). A pesquisa qualitativa tem como objetivos mais comuns compreender e discutir a revisão da literatura sobre o tema de pesquisa (TACHIZAWA; MENDES, 2006).

Assim, a discussão dos termos a respeito de gênero, políticas públicas e sociais permitirá a compreensão dos conceitos utilizados pelas várias áreas do conhecimento científico, o que proporcionará um melhor embasamento teórico da pesquisa em pauta. $O$ trabalho faz uso da pesquisa bibliográfica, com base em livros, periódicos, artigos científicos, teses, dissertações etc. O conhecimento pode ser construído por meio do diálogo estabelecido entre os autores selecionados e definidos para a composição do referencial teórico, proporcionando uma sustentação teórica que viabilizará o desenvolvimento do tema de pesquisa. Isto é, o levantamento bibliográfico definido para o projeto tem a finalidade de subsidiar a elaboração de conhecimento, que dará o fundamento para a análise, reflexão e discussão dos objetos e fenômenos da pesquisa (OLIVEIRA, 2007).

Este estudo também se utiliza, ainda, da pesquisa documental, pois ao pesquisar sobre as políticas públicas realizadas no RS faz uso da legislação estadual, no que diz respeito aos Decretos publicados, pelas duas últimas gestões do RS, sobre as políticas públicas para as mulheres. A pesquisa documental recorre a fontes mais diversificadas e dispersas, sem tratamento analítico, tais como tabelas estatísticas, jornais, revistas, relatórios, documentos oficiais, cartas, filmes, fotografias, pinturas, sites, relatórios de empresas, vídeos de programas de televisão etc. (FONSECA, 2002, p. 32). 
Revista Brasileira de História \& Ciências Sociais - RBHCS

Vol. $12 \mathrm{~N}^{\circ} 23$, Janeiro - Junho de 2020

\section{Políticas públicas de gênero e sua análise}

A conjuntura na qual o Brasil se encontra nos dias de hoje em relação à violência, em especial à violência de gênero, revela a crise que ainda assola a questão social no país. Pesquisas demonstram que os índices de violência contra as mulheres pela condição de gênero não param de crescer, como demonstram os registros de crime de ódio contra o gênero feminino os quais aumentaram $12 \%$, em 2018, refletindo que a cada duas horas uma mulher é morta no país pelo simples fato de ser mulher (USP, 2019).

Diante desse contexto, a desigualdade de gênero, que sempre se fez presente e constantemente foi e ainda é vista por muitos como natural, mostra-se como questão social, isto é, um tema que necessita de uma resposta, uma ação por parte do Estado e da sociedade. Logo, a desigualdade e, consequentemente, a violência de gênero como questões sociais demandam políticas públicas, sobretudo, políticas sociais. Sem a pretensão de tratar a temática com a profundidade que merece, mas o necessário para este trabalho, a seguir serão tratados alguns conceitos básicos como políticas públicas, políticas sociais e transversalidade.

Antes, porém, é importante fazer uma breve distinção entre Estado e governo. Considera-se Estado como a totalidade de instituições permanentes como órgãos legislativos, tribunais, exército e outras, que viabilizam a ação do governo. Governo, por sua vez, pode ser definido como conjunto de programas e projetos que políticos, técnicos, organismos da sociedade e outros propõem para a sociedade como um todo, de acordo com os interesses políticos de um determinado governo que está desempenhando as funções de Estado por um tempo estabelecido (HÖFLING, 2001).

Em relação às políticas públicas, pode-se dizer, nesse sentido, que é o Estado atuando, isto é, o Estado implantando um projeto de governo, por meio de programas dirigidos a setores específicos da sociedade, em que as políticas públicas são diretrizes de ação do poder púbico, normas e procedimentos utilizados nas relações entre ele, poder público e a sociedade. São políticas estruturadas em documentos, como leis, programas, linhas de financiamento, que orientam ações que geralmente compreendem recursos públicos (TEIXEIRA, 2002). 
Em suma, são a totalidade de ações, metas e planos que os governos (nacionais, estaduais ou municipais) traçam para alcançar o bem-estar da sociedade e o interesse público. Isto é, ações que os dirigentes públicos selecionam a fim de atender as expectativas da sociedade (elas podem ser econômicas, de gestão, de infraestrutura, sociais) ou necessidades, em especial, da parcela excluída da sociedade. Essas necessidades serão interpretadas e farão parte da agenda de quem ocupa o poder. Geralmente, são pautadas por meio da pressão, da mobilização da sociedade civil, a fim de ter reconhecidos, de ampliar e efetivar seus direitos de cidadania.

Dessa forma, evidencia-se que as políticas públicas passam por um processo de negociações, pressões, alianças que poderão ou não resultar nos interesses preponderantes da sociedade, tendo em vista que dependerão, além da pressão feita por parte da população, do entendimento e das escolhas daqueles que controlam o poder.

As políticas sociais são políticas públicas que explicitam espécime de proteção social por parte do Estado. Elas visam a desenvolver as responsabilidades públicas (estatais ou não) na promoção da seguridade social e do bem-estar da população (saúde, educação...), com o objetivo de diminuir as desigualdades estruturais produzidas, ocasionadas pelo desenvolvimento socioeconômico (HÖFLING, 2001).

Carvalho (2007) diz que a principal característica das políticas sociais é a transversalidade. A transversalidade garante uma ação integrada e sustentável entre as diversas instâncias governamentais e, consequentemente, o aumento da eficácia das políticas públicas. Em relação às mulheres, ela assegura uma governabilidade mais democrática e inclusiva, a fim de superar as assimetrias de gênero nas distintas esferas de governo (BANDEIRA, 2005). Adiante um sucinto panorama das políticas sociais dirigidas às mulheres.

Devido a uma cultura patriarcal, onde predominam o machismo e o sexismo, e, provavelmente, pela falta de ações mais efetivas por parte do Estado, as mulheres ainda hoje são alvos de violência de todos os tipos apenas pelo fato de serem mulheres. Diante disso, com o intuito de buscar a cidadania (PINTO, 2003), a igualdade de direitos, de tratamento, a diminuição da dominação masculina e da submissão das mulheres, o feminismo, no Brasil, desde o início dos anos de 1980, articulou-se em movimentos para acabar com a discriminação 
e a violência gerada contra elas. Com a busca por parcerias e pressionando o Estado a fim de tratar desse problema social, passou a exigir serviços e ações que buscassem enfrentar o problema da violência contra as mulheres (LAZZARI, 2014).

No entanto, muito antes, as mulheres já batalhavam contra a exclusão social e para mudar o estigma que sempre lhes fixou o papel, único e exclusivo, de reprodutoras, donas-de-casa e o caráter de fragilidade. Constam registros que a partir do século XVII já havia movimentos de mulheres requerendo igualdade sexual, estabelecendo-se, dessa forma, como o século que iniciou o feminismo (GARCIA, 2011).

Essa luta pela igualdade de direitos, a pressão das mulheres e do feminismo sobre o Estado fez com que nascessem políticas públicas nesse sentido. No Brasil, os estudos de gênero tornaram-se mais sólidos no final dos anos de 1970, junto com os movimentos feministas (FARAH, 2004). Nesse período, o país passava pela repercussão de um dos crimes passionais mais conhecidos do país: o caso “Doca Street”. Raul Fernando do Amaral Street, o Doca, matou sua namorada, Ângela Diniz, após uma violenta discussão entre o casal, em dezembro de 1976 (LAZZARI, 2014), sob a alegação de legítima defesa da honra.

Cabe salientar que até os anos de 1980 as políticas públicas que existiram no Brasil eram voltadas para as mulheres e não com o intuito de alterar desigualdades de gênero. Na sua maioria, as políticas públicas reforçavam os papéis sociais tradicionais e predominantes das mulheres (CARLOTO, 2004). As parcas políticas nesse sentido, então, levavam em conta o papel das mulheres como mães e “[...] lideranças para a recuperação e encaminhamento de jovens da comunidade para políticas sociais" (OTA, 2014, p. 59) quando, na verdade, essas atribuições devem ser do Estado. Além disso, essas políticas preocupavam-se mais em combater a violência contra as mulheres do que promover, ao mesmo tempo, sua autonomia, o empoderamento delas.

As primeiras políticas públicas brasileiras (década de 1980) com recorte de gênero foram a criação, no Estado de São Paulo, do primeiro Conselho Estadual da Condição Feminina (em 1983) e a primeira Delegacia de Polícia de Defesa da Mulher (em 1985). Após, teve a constituição do Conselho Nacional dos Direitos das Mulheres, pelo Ministério da Justiça (em 1985) e essas instituições 
Revista Brasileira de História \& Ciências Sociais - RBHCS

Vol. $12 \mathrm{~N}^{\circ} 23$, Janeiro - Junho de 2020

se disseminaram por todo o Brasil (FARAH, 2004, p. 51).

Trazendo a questão para o Estado do Rio Grande do Sul, esse foi apontado pelo Conselho Nacional de Justiça (CNJ) como sendo o segundo estado onde mais foram instaurados procedimentos policiais, visando ao cumprimento da Lei Maria da Penha entre julho de 2010 e novembro de 2011. Foram 81.197, ficando atrás apenas do Rio de Janeiro, com 157.430 procedimentos instaurados. Esses dados foram divulgados em abril de 2012, durante a $6^{\mathrm{a}}$ edição da Jornada Lei Maria da Penha, promovida pelo CNJ, e contabilizam, desde a abertura de inquéritos à instauração de ações penais e de medidas protetivas, entre outras medidas e procedimentos. Somado a esses dados, a Secretaria de Segurança Pública do Rio Grande do Sul (2014) demonstrou que em 2013 os registros policiais foram de 43.696 denúncias de ameaças, 26.179 de lesão corporal, 1.259 denúncias de estupros e 92 casos de feminicídios consumados e 229 registros feminicídios tentados, revelando como esses crimes continuam altos no RS (RIO GRANDE DO SUL, 2014a).

Atualizando esses dados, só no carnaval, dias $1^{\circ}$ a 06 de março, de 2019 o Ligue 180 recebeu 1.552 denúncias, entre elas, 114 tentativas de feminicídios, e o Estado do Rio Grande do Sul aparece em quinto lugar no número de denúncias nesse período, foram 1033. Ademais, o RS foi apontado pelo Conselho Nacional de Justiça (CNJ, 2018) como o Estado que mais expediu medidas protetivas de urgência, pois o Tribunal de Justiça (TJ) do RS emitiu em números absolutos, no ano de 2017, 38664 medidas protetivas.

Esses números podem demonstrar que as mulheres gaúchas denunciam mais ou que o RS é um dos estados onde mais existe violência de gênero. Não se pode deixar de salientar que esses números, ainda, são subdimensionados porque muitas mulheres continuam sem denunciar seus agressores, devido a alguns fatores como medo e/ou vergonha.

Talvez isso tenha sido reflexo da demora do RS em investir no combate à violência contra as mulheres, em políticas públicas direcionadas à proteção das mulheres em situação de violência. A prova disso é que o Estado foi o último a assinar o Pacto Nacional pelo Enfrentamento à Violência contra as mulheres, em vigor desde 2007. O RS aderiu ao Pacto apenas em 2011, dificultando, assim, a possibilidade de os municípios buscarem recursos. Porém a partir de 2011, com a assinatura do Pacto Nacional, os investimentos na Rede de Atendimento da 
Segurança Pública para o Enfrentamento à Violência Doméstica e Familiar pelo governo do RS aumentaram significativamente. Tanto é assim que esses investimentos foram reconhecidos, em 2014, pelo Banco Interamericano de Desenvolvimento (BID), na categoria ‘Governante: A Arte do Bom Governo’.

O governo do RS contou com uma Secretaria Estadual de Políticas Públicas para Mulheres (SPM-RS) de 2011 até o início de 2015. Pois quando o novo governo assumiu, em 2015, uma de suas primeiras medidas, com o intuito de cortar gastos, foi a extinção da SPM-RS, por meio da Lei 14.672, de $1^{0}$ de janeiro de 2015. A Secretaria, então, foi transformada em Departamento de Políticas para as Mulheres. Em 2017, essa secretaria recebeu o nome de Secretaria de Desenvolvimento Social, Trabalho, Justiça e Direitos Humanos e o Decreto $\mathrm{n}^{\mathrm{o}}$ 54.286, de 11 de outubro de 2018 descreve a sua estrutura, na qual prevê uma relação de órgãos, entre eles o Departamento de Políticas para Mulheres (RIO GRANDE DO SUL, 2017).

Ressalte-se que, ainda no governo de Tarso Genro, entre os anos de $2011 \mathrm{e}$ 2014, houve o Fórum Pró-Equidade de Gênero e Raça/Etnia, associado ao Programa Pró-Equidade de Gênero e Raça, objetivando condutas que visassem mais igualdade nos ambientes de trabalho, promoção da autonomia da mulher a partir de cursos gratuitos de 4 até 30 horas de duração. Não havia cobrança de inscrição. Tais cursos eram realizados, na sua maioria, em universidades do RS e tinham o investimento da SPM-PR em parceria com a Secretaria de Comunicação do Estado, a Fundação Cultural Piratini, a Fundação para Desenvolvimento de Recursos Humanos (ambas as Fundações foram extintas pelo atual governo, eleito em 2014), o Sindicato dos Jornalistas Profissionais do RS e as universidades. A partir dos cursos foi criado o Manual para Uso Não-Sexista da Linguagem, lançado em 2014, com o propósito de que os programas e ações tenham uma linguagem oral e escrita não sexista, não hierárquica e equitativa, assim como comportamentos e expressões discriminatórias sejam restringidos nas administrações públicas e pela sociedade de uma forma geral (RIO GRANDE DO SUL, 2014).

A SPM-RS, em 2013, instaurou a Rede Lilás com uma administração transversal e não hierárquica para incentivar a troca de informações entre os órgãos governamentais e não governamentais em relação às políticas públicas direcionadas para as mulheres. As principais ferramentas dessa Rede são o 
Telefone Lilás (central de apoio gratuito para monitorar a proteção das vítimas e acionar os organismos públicos e conselhos da mulher); a Patrulha Maria da Penha (que observa mulheres em medidas protetivas e seus agressores); as DEAMs; e as Casas Abrigo e de acolhida para as vítimas. Existem ainda as Salas Lilás, dentro das DEAMs e dos Postos de Atendimento à Mulher. São salas que permitem mais privacidade às vítimas, para que possam ficar isoladas de seus agressores na Delegacia, em casos de prisões em flagrante. Contam, ainda, com a possibilidade de serem feitos exames de corpo delito com peritos em sexologia forense e técnicas de entrevistas.

A Rede Lilás atua também no empoderamento material das mulheres, como por exemplo, o Programa RS Mais Igual. Esse programa promove o Crédito Lilás e cursos profissionalizantes, com o fim de transferir renda para investimentos e inclusão produtiva das mulheres integrantes da Rede. Porém, em 2015 “[...] essa linha crédito deixou de receber subsídios” (CONTERATTO; MARTINS, 2016, p. 19), o que ocasionou a falta de procura pelas mulheres.

Além disso, em 2013, foi implementado, dentro do Presídio Central de Porto Alegre, o Projeto Metendo a Colher, direcionado ao tratamento dos agressores, com o objetivo de romper com o ciclo da violência contra as mulheres. Esse mesmo Projeto está sendo inserido na Penitenciária Feminina Madre Pelletier, também em Porto Alegre, com intuito de prevenir a violência doméstica.

De acordo com o Plano Plurianual (PPA), 2012-2015, a Secretaria Estadual de Saúde, que buscava abranger questões de gênero e saúde, promoveu ações educativas para que houvesse redução das doenças físicas e psicológicas provenientes de violência doméstica e sexual e o acesso aos serviços de assistência e de saúde de um modo geral. A SPM-RS implantou, então, a Política Nacional de Atenção Integral à Saúde das Mulheres (PNAISM), a qual visou estabelecer normas que os hospitais devem seguir em relação aos direitos sexuais e reprodutivos, infecções sexualmente transmissíveis, métodos para fertilidade, prevenção e diagnóstico de câncer de colo de útero e de mama e cuidado com as mulheres em situação de violência e a educação dos profissionais dos Centros de Referência de Saúde (CONTERATTO; MARTINS, 2016, p. 13-14).

Em dezembro de 2014, mulheres vítimas de violência doméstica que possuíam medidas protetivas puderam contar com um novo serviço. Trata-se de um aplicativo de celular (PLP 2.0), ferramenta que surgiu da parceria entre a 
ONG Themis - Gênero e Justiça, o Tribunal de Justiça do Estado e instituições como a SSP-RS e a extinta SPM-RS.

O governo de José Ivo Sartori, entre os anos de 2015 e 2018, lançou em 2016, no Dia Internacional da Mulher, o programa de políticas públicas voltado para os direitos femininos intitulado "Mulher: Vida e Direitos". O programa era coordenado pelo Departamento de Política para Mulheres, e tinha como principais ações do governo: a criação do Fórum Estadual de Enfrentamento à Violência às Mulheres do Campo, da Floresta e das Águas e o fortalecimento da Rede Lilás, que são serviços integrados para articular ações voltadas às vítimas de violência. Outro objetivo foi a implantação e o fortalecimento de projetos voltados à promoção da autonomia da mulher, como a capacitação profissional e a inserção no mercado de trabalho.

A fim de examinar, empiricamente, a legislação estadual (RIO GRANDE DO SUL, 2011 a 2018) correspondente às gestões de Tarso Genro e José Ivo Sartori, isto é, do período de 2011 a 2018, em relação às políticas públicas voltadas às mulheres, constataram-se os seguintes números dessas políticas em cada ano de governo:

a) Governo de Tarso Genro com o total de 30 políticas públicas divididas seguinte forma: ano de 2011: 07; ano de 2012: 04; ano de 2013: 13 e ano de 2014: 06;

b) Governo de José Ivo Sartori com o total de 12 políticas públicas divididas da seguinte forma: ano de 2015: 06; ano de 2016: 03; ano de 2017: 03 e ano de 2018: 06.

A seleção da legislação consistiu, em primeiro lugar, na identificação de leis, decretos que incluíssem estrutura administrativa do poder executivo que fosse voltada para programas, planos, recursos financeiros dirigidos às mulheres como parte do público beneficiário, seja como foco específico da ação governamental ou por meio de convênios público-privado. Foram encontradas dentre as 30 legislações do governo de Tarso Genro, 22 decretos que destinavam verbas para conselhos e organismos de políticas para as mulheres e 1 decreto que instituiu programa de microcrédito para as mulheres. Em relação à gestão de José Ivo Sartori, dos 12 decretos, 7 previram recursos financeiros para a rede de atendimento às mulheres.

Diante do exposto, observou-se não apenas a diferença numérica das políticas públicas, mas contextualizando com seus planos de governo e notícias 
referentes a políticas para as mulheres, publicadas no site oficial do governo do $\mathrm{RS}$, também pode-se afirmar que houve diferença no tratamento que cada governo deu às questões relativas à violência contra as mulheres e ao empoderamento delas. Na gestão de Tarso Genro, foi assinado, em 2011, o Pacto de Enfrentamento à Violência contra as Mulheres, criado pelo governo federal em 2007, o qual previa entre outras medidas, recursos financeiros para os Estados aplicarem em políticas para as mulheres, essa gestão também criou a Secretaria de Políticas para as Mulheres (SPM). Foi, dessa forma, em comparação com o governo que o sucedeu, uma gestão que apresentou ações, políticas públicas, que visaram ao empoderamento das mulheres e ao combate à violência contra elas.

Enquanto que, na administração de José Ivo Sartori, além de se promoverem menos políticas públicas, como demonstrado nos poucos Decretos lançados em sua gestão, seu governos extinguiu a Secretaria de Políticas para as Mulheres (SPM), com a alegação de corte de gastos. Convém destacar que se tratava de uma Secretaria com o menor orçamento do Estado, na época.

Essas diferenças se refletem nos números de feminicídios no RS. Conforme o Observatório da Violência contra a Mulher, pertencente à Secretaria de Segurança Pública (RS), no final do governo de Tarso Genro, ano de 2014, o número de feminicídios era de 75, e em 2018, fim do governo de José Ivo Sartori, foram registrados 117 casos de feminicídios no Estado, ou seja, houve um aumento de $56 \%$.

Esses dados demonstram que, tendo em vista o período total de 8 anos, ambos os governos deram pouca prioridade às ações de empoderamento e de enfrentamento à violência contra as mulheres, confirmando que as relações entre a sociedade e o Estado refletem e incorporam fatores culturais. Um dos elementos importantes desse processo diz respeito justamente aos fatores culturais,

àqueles que historicamente vão construindo processos diferenciados de representações, de aceitação, de rejeição, de incorporação das conquistas sociais por parte de determinada sociedade. Com frequência, localiza-se aí procedente explicação quanto ao sucesso ou fracasso de uma política ou programas elaborados; e também quanto às diferentes soluções e padrão adotados para ações públicas de intervenção (HÖFLING, 2001, p. 39).

Salienta-se também que, além de proporcionar políticas públicas que fortaleçam as mulheres, que combatam a violência, os governos deveriam tomar 
certos cuidados na escolha das políticas sociais a serem aplicadas, pois algumas soluções acabam reforçando a cultura existente, segregando as mulheres ainda mais e não contribuem para uma sociedade mais igualitária, como por exemplo no caso do transporte público com a criação do vagão cor de rosa, posto que se tem dificuldade de expor e fazer com que os homens vejam que o que eles fazem está errado. Tendo em vista que, apenas a legislação existente, que por sinal é de grande valia e necessária, não tem sido suficiente diante da cultura patriarcal e sexista presente no país.

Porém, apesar de alguns equívocos, é evidente que as políticas sociais podem ser e são, ao contrário de meras reprodutoras das relações de dominação, um lugar, um meio para a transformação social. No entanto, para isso, é necessário que as políticas públicas voltadas às mulheres sejam transversais, que não visem apenas à segurança pública, com o combate à violência, mas que envolvam também a educação, a saúde, a economia, a fim de empoderar e dar tratamento igualitário para as mulheres. "Considerando que a libertação é sempre um ato social, o empoderamento é somente um pequeno passo em direção à libertação, sendo a conscientização o processo que possibilita a transformação social” (ROSO; ROMANINI, 2014, p. 83).

\section{Considerações finais}

Ao pensar que um discurso transmite e defende as ideias de uma pessoa, de um grupo, viu-se, no referencial teórico, que os homens criaram construções sociais para se beneficiarem em relação às mulheres, e essas de certa forma aceitaram esses papeis de gênero. As mulheres, ao aceitarem esses papeis de gênero que os homens lhes conceberam, isto é, ao reconhecer esse discurso, acabaram por reconhecer, conferir um poder a eles. Esse poder, então, é o que incide sobre as mulheres e finda na sujeição, submissão delas, pois elas veem como natural as diferenças de gênero, por consequência, as desigualdades.

Desse modo, não apenas as mulheres internalizam essas desigualdades e assumem os papeis que os homens projetaram para elas, como elas e os homens consideram que essa forma de agir criada para as mulheres é a única maneira correta de atuar e ser. Surge, então, o que se chama de identidade de gênero. 
Sendo assim, a identidade de gênero é a maneira de categorizar o lugar de um indivíduo, de um grupo em uma determinada cultura.

Essa categorização produz diferenças e desigualdades social, econômica e política que geram a violência de gênero. Violência, essa, advinda da dominação masculina que, na maior parte dos casos, foi e ainda está incutida em homens e mulheres de maneira invisível, fato que acaba por mascarar o poder dos homens nas relações, é uma das causas que torna tão difícil o seu combate e a mudança da condição das mulheres na sociedade.

O feminismo, no início dos anos de 1980, teve um papel importante no Brasil, pois articulou-se em movimentos para acabar com a discriminação e essa violência gerada contra as mulheres brasileiras. As mulheres pressionaram o Estado a fim de tratar desse problema social, exigindo políticas públicas na forma de serviços e ações que buscassem enfrentar o problema da violência contra as mulheres.

Entendem-se as políticas públicas como a totalidade de ações, planos que os governos, nas três esferas de poder, nacional, estadual ou municipal, que traçam para alcançar o bem-estar da sociedade e o interesse público. Ao pensar em bem-estar das mulheres, viu-se que o mais adequado é falar em políticas sociais, pois elas são, na realidade, políticas públicas que explicitam padrão de proteção social por parte do Estado e visam a desenvolver as responsabilidades públicas, estatais ou não, na promoção da seguridade social e do bem-estar da população mais vulnerável, com o objetivo de diminuir as desigualdades existentes na sociedade.

Ao examinar os dois últimos governos do Estado do RS pôde-se observar aspectos bem distintos em relação às questões de gênero, ou melhor, às políticas sociais para as mulheres. Na gestão de Tarso Genro, verificaram-se, na legislação estadual do seu período de governo, 30 políticas públicas que proporcionaram ações no sentido de tentar empoderar o feminino e diminuir a violência contra as mulheres por meio de medidas como a adesão ao Pacto de Enfrentamento à Violência contra as Mulheres, a criação da Secretaria de Políticas para as Mulheres (SPM) e investimentos financeiros nos organismos destinados ao enfrentamento à violência de gênero.

Por outro lado, na gestão de José Ivo Sartori, foram encontradas apenas 12 políticas públicas voltadas para as mulheres durante os quatro anos de sua gestão. 
Averiguou-se, então, que poucos recursos financeiros foram destinados a melhorar as condições das mulheres no Estado e que foi extinta a Secretaria de Políticas para as Mulheres (SPM), com a alegação de corte de gastos. Essa justificativa gerou indignação em muitas gaúchas e gaúchos, pois o que se questionou foi que o corte de gastos realizou-se às custas do ataque aos direitos humanos das mulheres, sem levar em conta, também, que não foi considerado o fato de que se tratava de uma Secretaria com o menor orçamento.

O fim da SPM representou, além da perda na autonomia, também a perda da visibilidade e da prioridade dentro da administração estadual. Em suma, pôdese constatar que esse governo com suas poucas políticas públicas e com a extinção da SPM representou um retrocesso nas políticas sociais para as mulheres e refletiu, na sua maneira de governar, a cultura machista, patriarcal existente no RS.

Assim, viu-se não apenas o contraste numérico das políticas sociais para as mulheres, entre uma gestão e a outra, mas também como a cultura patriarcalista influenciou mais a gestão de José Ivo Sartori. Essas diferenças encontradas entre os governos de Tarso Genro e José Ivo Sartori tiveram uma grave repercussão que se revelou nos números de feminicídios no Estado, isto é, foi registrado um aumento de $56 \%$ nos casos de feminicídios entre o término de uma gestão e o término da outra.

Portanto, diante desses dados e tendo em vista que as mulheres ainda se encontram em posição de desigualdade na sociedade e sofrendo violência de gênero, é de fundamental importância desenvolver políticas que identifiquem, reconheçam as desigualdades econômicas, políticas e sociais entre homens e mulheres, pensando numa dialética de políticas públicas de gênero, com ações voltadas para o fortalecimento das meninas e das mulheres, visto que a desigualdade de gênero é a base da violência contra as mulheres. Porém, não é apenas com a ação do Estado que se conseguirá mudar a cultura da sociedade brasileira, que ainda torna possível e tolera as violações contra as mulheres. É essencial envolver toda a sociedade, incluir os homens e os meninos na busca pela equidade de gênero.

Para que se tenha essa contribuição, é importante mostrar aos meninos e aos homens que a diferença de gênero não tem que ser seguida de desigualdade. 
Revista Brasileira de História \& Ciências Sociais - RBHCS

Vol. $12 \mathrm{~N}^{\circ} 23$, Janeiro - Junho de 2020

Por isso a importância da educação, seja ela formal ou informal, nesse processo. Mas, isso não é o suficiente.

As mulheres também precisam continuar lutando, principalmente, por mais espaços no Poder, ocupando cargos de poder e de decisão, para que realmente se consigam transformações concretas, com políticas que reflitam a diversidade e a igualdade de gênero, enfim com demandas por novos e mais amplos direitos sociais. Pois, não se pode esquecer que o Brasil é composto na sua maioria por mulheres porém, os cargos de poder ainda são compostos por mais homens, os quais, na maior parte, apresentam comportamento patriarcalista e machista.

\section{Referências}

ARAÚJO, Rita de Cássia Barbosa de. O voto de saias: a Constituinte de 1934 e a participação das mulheres na política. Revista Estudos Avançados, v. 17, n. 49. São Paulo, 2003.

ARENDT, Hannah. Sobre a violência. Rio de Janeiro: Relume Dumará, 1994. BANDEIRA, Lourdes. Fortalecimento da Secretaria Especial de Políticas para as Mulheres: avançar na transversalidade da perspectiva de Gênero nas Políticas Públicas. Brasília: SPM, 2005. Disponível em:

http://www.observatoriodegenero.gov.br/menu/publicacoes/outros-artigos-epublicacoes/fortalecimento-da-secretaria-especial-de-politicas-para-as-mulheresavancar-na-transversalidade-da-perspectiva-de-genero-nas-politicaspublicas/view, acesso em: 29/abr/2019.

BOURDIEU, Pierre. A dominação masculina. Rio de Janeiro: Bertrand Brasil, 2003.

BRASIL. Cidadania e Justiça. Pacto Nacional pelo Enfrentamento à Violência contra as Mulheres, 2011. Disponível em:

http://www.brasil.gov.br/cidadania-e-justica/2011/05/rio-grande-do-sulassina-pacto-pelo-enfrentamento-a-violencia-contra-as-mulheres, acesso em: 10/abr/2019.

BRASIL. Secretaria de Políticas para as Mulheres. III Plano Nacional de Políticas para as Mulheres. Brasília, 2013. Disponível em: http://www.compromissoeatitude.org.br/plano-nacional-de-politicas-para-asmulheres-2013-2015-spm-pr-2013/, acesso em: 20/abr/2017.

BRASIL. Secretaria de Políticas para as Mulheres. Ligue 180. Balanço Anual/2016. Brasília, 2016. Disponível em:

http://www.spm.gov.br/assuntos/violencia/ligue-180-central-de-atendimentoa-mulher/balanco-anual-180 2016.pdf, acesso em: 18/jul/2018. 
BRASIL. Secretaria de Políticas para as Mulheres. Rede de Enfrentamento, 2011. p. 13. http://www.spm.gov.br/publicacoes-

teste/publicacoes/2011/redede-enfrentamento, acesso em 16/mar/2014.

BRASIL. Senado Federal. Secretaria de Transparência - DataSenado, jun. de 2017. Disponível em: https://www12.senado.leg.br/institucional/datasenado. Acesso em: 8/jun/2017.

CARLOTO, Cássia Maria. Ruptura ou reforço da dominação: gênero em perspectiva. In: Políticas Públicas e igualdade de gênero, São Paulo, Caderno 8 da Coordenadoria Especial da Mulher, 2004.

CARVALHO, Ailton Mota de. Políticas sociais: afinal do que se trata? Agenda

Social. Revista do PPGPS / UENF. Campos dos Goytacazes, v.1, n.3, set-dez/2007, p. 73-86. Disponível em:

http://www.uenf.br/Uenf/Downloads/Agenda Social 5075 1204236093.p df, acesso em: 28/abr/2019.

CAVALCANTI, Stela Valéria Soares de Farias. Violência Doméstica: análise da lei "Maria da Penha", nº 11.340/o6. Salvador, BA: Edições PODIVM, 2007.

CONSELHO NACIONAL DE JUSTIÇA. O Poder Judiciário na Aplicação da Lei Maria da Penha 2018. Disponível em: https://www.cnj.jus.br/wpcontent/uploads/2018/06/5514bodebfb866190c20610890849e10 1c3f3d621d a010274f3d6ge6a6d6b7e6.pdf, acesso em: 16/dez/2019.

CONTERATTO, Deisi; MARTINS, Clitia Helena Backx. Transversalidade e integração em políticas públicas de gênero: análise da Rede Lilás no Rio Grande do Sul. Secretaria do Planejamento, Mobilidade e Desenvolvimento Regional. Fundação de Economia e Estatística, 2016.

CUNHA, Tânia Rocha de Andrade. O preço do silêncio: mulheres ricas também sofrem violência. Vitória da Conquista: Edições Uesb, 2007.

DINIZ, Gláucia Ribeiro Starling; PONDAAG, Miriam Cássia Mendonça. A Face Oculta da Violência contra a Mulher: o Silêncio como Estratégia de Sobrevivência. In: ALMEIDA, Angela Maria de Oliveira (Org.) [et. al.]. Violência, exclusão social e desenvolvimento humano: estudos em representações sociais. Brasília: Editora Universidade de Brasília, 2006.

DIREITOS HUMANOS. Declaração para Eliminação da Violência Contra as Mulheres. Disponível em: http://direitoshumanos.gddc.pt/3 4/IIIPAG3 4 7.htm, acesso em: 6/ jun/2013.

DIREITOS HUMANOS. Conferência Mundial dos Direitos Humanos. Disponível em: http://www.dhnet.org.br/direitos/anthist/viena/viena.html, acesso em: 30/maio/2013.

FARAH, Marta Ferreira Santos. Gênero e políticas públicas. Revista Estudos Feministas, Florianópolis, janeiro-abril/2004. Disponível em: http://www.scielo.br/pdf/ref/v12n1/21692. Acesso em: 20 abr. 2017.

FONSECA, João José Saraiva. Metodologia da pesquisa científica. Fortaleza: UEC, 2002. Apostila. 
FOUCALT, Michel. Em Defesa da Sociedade: Curso do Collège de France. Tradução Maria Ermantina Galvão. São Paulo: Martins, 1999.

GARCIA, Carla Cristina. Breve história do feminismo. São Paulo: Claridade, 2011.

GIORDANI, Annecy Tojeiro. Violências contra a Mulher. São Caetano do Sul: Yendis Editora, 2006.

GROSSI, Patrícia Krieger. Violência contra a mulher: implicações para os profissionais da saúde. In: LOPES, Marta Julia Marque; MEYER, Dagmar Estermann; WALDOW, Vera Regina (Orgs.). Gênero e Saúde. Porto Alegre: Artes Médicas, 1996.

GROSSI, Patrícia Krieger; AGUINSKY, Beatriz Gershenson. Por uma nova ótica e uma nova ética na abordagem da violência contra as mulheres nas relações conjugais. In: GROSSI, Patrícia Krieger; WERBA, Graziela C. (Orgs.).

Violências e Gênero: coisas que a gente não gostaria de saber. Porto Alegre: EDIPUCRS, 2010.

GROSSI, Miriam Pillar. Rimando amor e dor: reflexões sobre a violência no vínculo afetivo-conjugal. In: PEDRO, Joana M.; GROSSI, Miriam Pillar.

Masculino, feminino, plural: gênero na interdisciplinariedade.

Florianóplos: Ed. Mulheres, 1998.

GROSSI, Miriam Pillar. Identidade de gênero e sexualidade. Antropologia em primeira mão. Florianópolis, p. 1-18, 1998. (Versão revisada - 2012).

Disponível em: www.miriamgrossi.cfh.prof.ufsc.br/publicações.html, acesso em: 29/out/2012.

HEISE, Lori. Violence against Women: The Hidden Health Burden. Relatório Preparado para o Banco Mundial, 1994 (Mimeo.) (Manuscrito publicado sob o mesmo título, na série World Bank Discussion Papers 255, Washington, D.C.: World Bank, 1994).

http://wwwwds.worldbank.org/servlet/WDSContentServer/WDSP/IB/1999/o 4/28/ooooo9265_3970716144635/Rendered/PDF/multiopage.pdf, acesso em: 28/mar/ 2014 .

HIRIGOYEN, Marie-France. A violência no casal: da coação psicológica à agressão física. Rio de Janeiro: Bertrand Brasil, 2006.

HÖFLING, Eloisa de Mattos. Estado e Políticas (Públicas) Sociais. Cadernos Cedes, ano XXI, n. 55, novembro/2001. Disponível em: http://www.scielo.br/pdf/ccedes/v21n55/5539, acesso em: 28/abr/2019.

LAZZARI, Kellen. Violência de gênero: uma análise a partir do Centro de Referência Para Mulheres Vítimas de Violência - Patrícia Esber. 2014. 117 p. Dissertação (Mestrado em Memória Social e Bens Culturais) - UNILASALLE, Canoas, 2014.

MEYER, Dagmar Estermann. Gênero e Educação: teoria e política. In: LOURO, Guacira Lopes; NECKEL, Jane Felipe; GOELLNER, Silvana Vilodre (Orgs.). Corpo, Gênero e sexualidade: um debate contemporâneo na educação. Petrópolis: Vozes, 2003.

MILLET, Kate. Sexual Politics. New York: Doubleday \& Company: 1970. 
MINAYO, Maria Cecília de Souza (Org.). Pesquisa social: teoria, método e criatividade. Petrópolis: Vozes, 2001.

OLIVEIRA, Maria Marly. Como fazer pesquisa qualitativa. Petrópolis: Editora Vozes, 2007.

OTA, Maria Eduarda. Gênero na Teoria Crítica e nas Políticas Públicas: a Dicotomia Público/Privado em Perspectiva. 2014. 91 p. Dissertação (Mestrado em Ciências Sociais - Pontifícia Universidade Católica do Rio Grande do Sul, Porto Alegre, 2014.

PESAVENTO, Sandra. A construção da diferença: cidadania e exclusão social. In:_ Uma outra cidade: o mundo dos excluídos no final do século XIX. São Paulo: Cia. Editora Nacional, 2001.

Sensibilidades: escrita e leitura da alma. In: PESAVENTO, Sandra; LANGUE, Frédérique. Sensibilidades na história: memórias singulares e identidades sociais. Porto Alegre: Editora da Universidade/UFRGS, 2007.

PERROT, Michelle. Os excluídos da história: operários, mulheres e prisioneiros. Rio de Janeiro: Paz e Terra, 2001.

PINTO, Céli Regina Jardim. Uma história do feminismo no Brasil. São Paulo: Fundação Perseu Abramo, 2003. (Coleção História do Povo Brasileiro).

RIO GRANDE DO SUL. Secretaria de Políticas para as Mulheres. Manual para uso não sexista da linguagem. Porto Alegre, 2014. Disponível em:

http://www.spm.rs.gov.br/upload/1407514791 Manual\%2opara\%20uso\%20n\% C3\%A30\%20sexista\%20da\%2olinguagem.pdf, acesso em: 14/nov/2014. RIO GRANDE DO SUL. Secretaria de Políticas para as Mulheres. Relatório Final do Planejamento Integral Básico do Rio Grande do Sul para o Pacto de Enfrentamento à Violência contra as mulheres. Porto Alegre, 2014a.

RIO GRANDE DO SUL. Secretaria de Desenvolvimento Social, Trabalho, Justiça e Direitos Humanos. Porto Alegre, 2017.

RIO GRANDE DO SUL. Assembleia Legislativa, legislação estadual, 2011 a 2018. Disponível em:

http://www.al.rs.gov.br/legislativo/legisla\%C3\%A7\%C3\%A3oEstadual.aspx, acesso em: 23/mar/2019.

RIO GRANDE DO SUL. Secretaria de Segurança Pública. Observatório da Violência contra a mulher. Disponível em: https://www.ssp.rs.gov.br/indicadores-da-violencia-contra-a-mulher, acesso em: 16/dez/2019.

ROSO, Adriane; ROMANINI, Moises. Empoderamento individual, empoderamento comunitário e conscientização: um ensaio teórico. Psicologia e Saber Social, 3(1), 83-95, 2014.

SAFFIOTI, Heleieth Iara Bongiovani. Gênero, Patriarcado e Violência. São Paulo, SP: Fundação Perseu Abramo, 2004.

SANTOS, Cecília MacDowell; IZUMINO, Wânia Pasinato. Violência contra as Mulheres e Violência de Gênero: Notas sobre Estudos Feministas no Brasil, 2005. Disponível em: http://www.nevusp.org/downloads/downo83.pdf, acesso em: 6/maio/2014. 
SCOTT, Joan. Gênero: uma categoria útil de análise histórica. Educação e Realidade, Porto Alegre, v. 16, n. 2, p. 5-22, jul./dez., 1990. Gênero: uma categoria útil de análise histórica. Educação e

Realidade, Porto Alegre, v. 20, 71-99, 1995.

SOUZA-LOBO, Elisabeth. A classe operária tem dois sexos: trabalho, dominação e resistência. São Paulo: Brasiliense, 1991.

STOLCKE, Verena. La mujer es puro cuento: la cultura del género. In: Estudos Feministas, Florianópolis, 12(2): 264, maio/ago. 2004. Disponível em: http://www.scielo.br/pdf/ref/v12n2/23961.pdf, acesso em: 24/jun/2014.

STREY, Marlene Neves. Aprendendo a Ser Inferior: As Hierarquias de Gênero. In: STREY, Marlene Neves; LYRA, Ângela Villachan; XIMENES, Lavínia de Melo e Silva (Orgs). Gênero e Questões Culturais: a vida de mulheres e homens na cultura. Recife: Ed. Universitária da UFPE, 2002.

Gênero e Ciclos Vitais. In: STREY, Marlene Neves Strey [et al.]

(Orgs.). Gênero e Ciclos Vitais: desafios, problematizações e perspectivas. Porto Alegre: Edipucrs, 2012.

TACHIZAWA, Elio Takeshy e MENDES, Gildasio Alvares Filho. Como fazer monografia na prática. 12 ed. Rio de Janeiro: Editora FGV, 2006.

TEIXEIRA, Elenaldo Celso. O Papel das Políticas Públicas no Desenvolvimento Local e na Transformação da Realidade. AATR-BA, 2002. Disponível em:

http://www.dhnet.org.br/dados/cursos/aatr2/a pdf/o3 aatr pp papel.pdf, acesso em: 28/abr/ 2019.

TELES, Maria Cunha de Almeida; MELO, Mônica de. O que é violência contra a mulher? São Paulo: Brasiliense, 2002. 